\title{
Bienes producidos por poblaciones pobres que con capacitación, apoyo económico y concesiones pueden dejar de ser pobres
}

\author{
Goods produced by poor populations that with training, \\ economic support and concessions, can no longer be poor
}

\begin{abstract}
RESUMEN
En nuestro país todos somos testigos del nivel de podredumbre en lo ético y moral en las más altas esferas del poder político, la justicia y poder ejecutivo. En tres décadas propios y extraños robaron al país más de $\$ 70,000 ` 000,000$ millones de dólares, al margen de ello, los grandes, medianos, pequeños y micro empresarios continúan empeñados en lograr sus objetivos empresariales para el presente y los siguientes años.

Este año 2019 a pesar de la enorme crisis política en la que nos encontramos, tendremos un ligero incremento en las exportaciones del sector agrario, la mayor participación en ella, la tendrán los grandes y medianos empresarios agrícolas de la Costa, en función a la cantidad de recursos con que se dispone en esta región natural. En cambio, en la regiones naturales de sierra y selva millones de familias agrarias, viven conjuntamente con sus producciones en situación de pobreza y pobreza extrema por no contar con similares recursos, en este sentido se requieren urgentemente determinar una visión del sector fijando objetivos de inclusión económica social y, sus correspondientes estrategias y planes de acción de corto, mediano y largo plazo sobre crecimiento y desarrollo agrario basada en ordenamiento territorial con asignación de multi recursos, a fin de aprovechar las grandes oportunidades y el enorme potencial productivo de nuestros territorios agrarios, frente a innumerables acuerdos comerciales y mercados como consecuencia de la globalización y, de este modo, poder superar gradualmente la pobreza extrema y pobreza en este sector. Los objetivos involucran cobertura de demanda interna en la que se incluyen compras del estado con asignación de proveedores asociativos exclusivos y, de igual forma la generación de producciones con ofertas exportables.
\end{abstract}

Palabras claves: Minifundio; pobreza rural; unidades agrarias de producción; agricultura familiar; cooperativismo agrario rural.

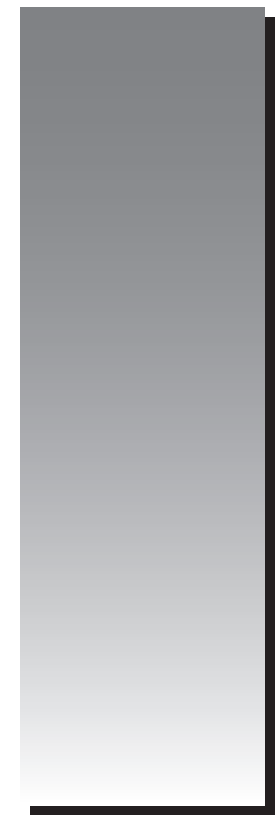

Juan Manuel Barreda Guerra

jbarredag1@unmsm.edu.pe Universidad Nacional Mayor de San Marcos. Lima, Perú

Presentado: 17/02/2021 - Aceptado: 01/03/2021 - Publicado: 17/06/2021

(C) Los autores. Este artículo es publicado por la revista Gestión en el Tercer Milenio de la Facultad de Ciencias Administrativas Universidad Nacional Mayor de San Marcos. Este es un artículo de acceso abierto, distribuido bajo los términos de la licencia Creative Commons Atribución 4.0 Internacional (CC BY 4.0) [https://creativecommons.org/licenses/by/4.0/deed.es] que permite el uso, distribución y reproducción en cualquier medio, siempre que la obra original sea debidamente citada de su fuente original. 


\begin{abstract}
We all witness the level of ethical and moral rot in the highest spheres of politics in our country, in three decades of our own and strangers robbed us of more than $70,000^{\prime} 000,000$ million dollars, even so, the large, medium, small and micro Entrepreneur are still determined to achieve their business objectives.

This year 2019, despite the enormous political crisis in which we find ourselves, we will have a slight increase in exports of the agricultural sector, the largest participation in it, will be the large and medium agricultural entrepreneurs of the Coast, depending on the amount of resources available in this natural region. On the other hand, in the natural regions of the Sierra and the jungle millions of agrarian families live together with their productions in situations of poverty and extreme poverty because they do not have similar resources, in this sense they urgently need to determine a vision of the sector setting goals of inclusion economic and, corresponding strategies and action plans of short, medium and long term on agricultural growth and development based on territorial planning with multi-resource allocation, in order to take advantage the great opportunities and the enormous productive potential of our agricultural territories in the face of countless trade agreements and markets as a result of globalization and, thus, gradually overcome extreme poverty and poverty in this sector. The objectives involve coverage of internal demand that includes state purchases with the allocation of exclusive associative suppliers and, in the same way, the generation of productions with exportable offers.
\end{abstract}

Keywords: Smallholding; rural poverty; agricultural production units; family farming; rural agricultural cooperativism.

\section{INTRODUCCIÓN}

La investigación deriva en ella luego de haber explorado preliminarmente algunas producciones de tipo manufactureras, alimentarias, textiles y agraria, producciones que en diversas ocasiones fueron ofertadas al estado para su adquisición, y que, a su vez este, consideraba pertinente su adquisición en función a la puesta en práctica de programas de adquisiciones del estado como un medio de apoyo a la micro y pequeña empresa, si bien es cierto es algo muy positivo, empero, se advirtió en la exploración que, el impacto económico de este hecho sucedería en poblaciones pequeña de empresarios que iban desde un micro o pequeño empresario hasta grupos de quince, veinte o treinta pequeños empresarios asociados. Sin embargo, al continuar las exploraciones en el sector agrario se halló poblaciones con centenares de miles de familias productoras agrarias en condiciones de pobreza que, cumplían los criterios de selección planteados como población objetivo de estudio, en las que se cumplía la motivación de la investigación en encontrar ofertas y demandas cuya producciones pudieran ser concesionadas por el estado como proveedores toda vez que estas cumplieran con estándares de calidad, servicios y precios competitivos, a fin de adquirir sus producciones como forma de asegurarles mercados de manera sostenible a precios justos.

Explorar sectores de Participación productiva y comercial en unidades agrarias, en los que, el agente transformador y creador de valor cuente con tres aspectos fundamentales siguientes: Amplio conocimiento del sector y experiencia real en la creación de valor de su producción y/o servicio, cuente con un medio propio o en posesión para la creación de valor y, se encuentre comprendido dentro de la población de pobreza monetaria y que, el tamaño de la población de impacto a la que pertenece sea infinita.

El sector agrario y sub sector agro industrial llevan sobre sus hombros la enorme responsabilidad del aseguramiento de la nutrición y alimentación de la población, dicha misión debe cumplirla bajo estándares de calidad, servicios y precios accesibles para las familias 
y ciudadanos, por tanto, requiere de ciertos factores de productividad y competitividad a fin de brindar una atención eficiente y, no permitir importaciones que, atiendan la demanda de ciertos productos agrarios básicos de la alimentación popular. Para el logro de esta responsabilidad talla muchísimo la realidad nacional del sector, en el caso nuestro, somos un país con una estructura agraria atomizada por minifundios, el $85 \%$ son parcelas con menos de tres hectáreas de tierra cultivable, esta situación es la herencia que nos dejó la Reforma Agraria efectuada por la Junta Revolucionaria del General, Juan Velasco Alvarado. En minifundios es difícil lograr producciones con economías de escala significativas que reflejen productividad y competitividad, peor aún, si, no se cuente con recursos económicos para invertir en nuevas tecnologías, conocimientos, viajar y aprender de otras realidades, entre otros recursos necesarios para la producción agraria eficiente que sea capaz de unirse en cadenas de valor, de comercialización o logísticas, clúster, o alianzas estratégicas productivas $\mathrm{y}$, asociatividad cooperativa.

En nuestro país, la región natural que más cuenta con recursos diversificados es la costa, en razón de que, cuenta con infraestructura e interconexión vial, puertos, aeropuertos, bancos e instituciones financiera, redes de información y comunicación con mercados nacionales e internacionales, compañías de seguros, transportes múltiples, energía, agua, oferta de paquetes tecnológicos, mano de obra capacitada, servicios de cadena de frio, depósitos de almacenamiento entre otra diversidad de recursos disponibles y, lo fundamental, pues se trata del gran capital invirtiendo conjuntamente con la banca y sus asociados grupos de intereses en el agro peruano.

Estos hechos explican cómo los grandes capitales agrarios que operan en la costa de nuestro país, han sabido aprovechar las oportunidades brindadas por los Tratado de Libre Comercio con Estados Unidos y múltiples países, el TLC con EE.UU. entró en vigencia a partir del año 2009, sin embargo, nuestro país en el año 2000 solo contaba con un nivel de exportaciones agrarias del orden de los $\$ .800^{\prime} 000,000 \mathrm{mi}-$ llones de dólares $y$, tras los convenios internacionales alcanza desde el año 2009 al 2018 un nivel de exportaciones agrarias del orden de los \$7,030’000,000 millones de dólares, siendo el principal socio comercial estratégico de nuestro país los Estados Unidos de Norte América.

En contra partida con esta situación, vemos que, en las regiones naturales de sierra y selva y algunas zonas de la costa, existen innumerables parcelas en posesión de agricultores y familias con tres o menos hectáreas que viven en niveles de pobreza extrema y pobreza aun cuando trabajan sus cultivos que, generalmente son orientados en función al clima, la zona, temporada de siembra del cultivo y condiciones de la tierra, circunstancias que, sí le sumamos la falta de créditos para levantar capital de trabajo para sus tierras, imposibilidad de acceder a recursos como paquetes tecnológicos de semillas mejoradas, seguros contra clima, plagas, desastres, información sobre mercados, comunicaciones, falta de infraestructura vial, inexistencia de capacitaciones sobre manejo de riego, abono y pesticidas autorizados internacionalmente en siembras y cultivos, escases de energía y precios altos de los mismos, problemas en la disponibilidad y calidad de agua, escasa mano de obra especializada, uso de tecnología de siembra, cultivo y cosecha entre otros recursos, veremos que verdaderamente estos agricultores trabajan sus tierras porque Dios es peruano, la gran mayoría de agricultores conoce sus trabajos y cultivos y saben que, contando con apoyo económico e información sobre oportunidades de mercado pueden levantar la productividad de sus tierras en $50 \%$ y duplicar su producción con altos estándares de calidad y precios en cultivos como el maíz amarillo duro, la caña de azúcar, frijol, cacao y café, alcanzarían niveles de producción con economías de escala que produzcan y le permitan mejorar la rentabilidad de sus producciones y consecuentes ingresos que mejorarían sus niveles de vida.

En territorio andino y de selva es visible y notoria la ausencia de estado que permite que nuestro país se dé el lujo de ser un país en pleno siglo XXI con agricultura desordenada, atomizada por minifundios, improductiva, alejada de mercados internacionales y de la competitividad empresarial y, lo más penoso, ser territorios con alta concentración de población en condiciones socio económicas de pobreza y pobreza extrema. 
Escobal y Armas (2015), en su trabajo sobre Estructura Agraria y dinámica de la pobreza rural en Perú, refieren que:

Los resultados econométricos sugieren que un importante determinante de la dinámica de pobreza rural observada es el tamaño de la propiedad, y no la estructura agraria. El tamaño promedio de la unidad agropecuaria no solo tiene un efecto lineal sobre el ratio de bienestar o sobre la pobreza rural, sino que además existe una importante no linealidad. Adicionalmente, se muestra que las provincias cuya tasa de emigración es más alta y cuya tasa de inmigración es más baja - esto es, aquellas cuyas condiciones no atraen capital humano- son las que sufren un mayor incremento de la pobreza rural. (pp. 7-8)

Estos hechos y su soslayamiento conllevan a la formación de círculos viciosos que contribuyen a la cronicidad de la pobreza.

El 22 de diciembre del 2012 durante el gobierno del presidente Ollanta Humala Tasso se promulgo la ley N. 29972 de Promoción de la Inclusión del Pequeño Productor Agrario a través de las Cooperativas con el propósito de formalizarlas asociativamente y mejorar su productividad para mejorar su capacidad de negociación mediante el logro de economías de escala. Lamentablemente, esta ley hasta el día de hoy no ha dado buenos resultados, son escasos los logros positivos de esta ley, más ha sido el enorme gasto del estado al mantener una inmensa burocracia sin lograr beneficio alguno para la población objetivo.

Con lo expuesto es conveniente entender que, alcanzar competitividad en producción y comercialización es muchísimo más que un discurso o slogan político con el cual pretendemos impresionar, hoy en día la única forma de convencer es con decisiones bien tomadas. Alcanzar competitividad es un serio esfuerzo y compromiso nacional en muchos aspectos en los que debe primar el criterio de sostenibilidad. En este sentido en la presente investigación se ha llegado al convencimiento que, con cinco productos agrarios con los cuales se alcance un eficiente nivel de competitividad interno y mundial, se lograría reducir significativos porcentajes de extrema pobreza y pobreza de manera significativa en los territorios o zonas de producción de dichos productos con políticas de estado de inclusión y apoyo técnico económico basadas en crecimiento y desarrollo territorial con aseguramiento de mercado.

La metodología utilizada para medir producciones, productividad y competitividad de las comunidades agrías basadas en estudios sociológicos realizados antes de la globalización han caído por tierra y desuso. La nueva dinámica de mercados impuesta por la globalización exige y aplica enfoque de territorio a fin de productivizar las producciones bajo políticas de estado a efecto de orientar recursos a planes concretos de crecimiento y desarrollo determinados para territorios agrarios seleccionados por sus producciones que se encuentren incluidos en los objetivos de desarrollo del sector mediante su conectividad y participación en mercados internos y externos.

\section{MÉTODOS}

El método de identificación de producto seleccionado para el estudio ha sido exploratorio referente a: Cantidad de familias rurales agrarias, denominadas unidades agrarias de producción dedicadas a la siembra y cultivo de productos que cuentan con gran demanda interna y de comercio exterior; cantidad de hectáreas en posesión o propiedad de la familias, disponibilidad de recursos económicos, tecnológicos, seguros, energía, agua, calidad de semillas, infraestructura vial, conexión con mercados interno y externo, productividad de sus tierras, ingresos. Con el análisis y evaluación de estas variables contrastar los ingresos de las familias contra la canasta básica familiar rural y general, a fin de sopesar los ingresos logrados por sus esfuerzos productivos y el nivel de vida que consiguen con sus ingresos para mantener a sus familias.

Los productos seleccionados bajo las variables expuestas han sido: Maíz Amarillo DuroMAR, Caña de azúcar (para producción de azúcar), Frijol Castilla, Café y Cacao. Las variables encontradas para estas poblaciones fueron:

El $85 \%$ de las familias poseedoras de 933,149 hectáreas en las que, se siembran los cinco productos seleccionados, son familias que 
se encuentran en condición de pobreza o pobreza extrema por consecuencia de falta de ordenamiento en la producción agraria, leyes prospectivas que fomenten el crecimiento y desarrollo de la agricultura peruana y la crónica historia de los escases de recursos para el agro de costa, sierra y selva. El presupuesto del sector agrario para el año 2020 asciende a 5,605'000,000 millones de soles del cual el $68 \%$ será utilizado en gastos corrientes, restando 32\%, 1,793,600,000 para inversión y obras, monto que es totalmente insuficientes para el ordenamiento, crecimiento y desarrollo del agro y su consecuente disminución y posible erradicación de la dramática pobreza en la que viven centenares de miles de familias peruanas encargadas de la responsabilidad de asegurar nuestra nutrición y alimentación. Las cifras demuestran la incoherencia del sistema, vale decir destinar al gasto burocrático el $200 \%$ de la cifra que se destina a inversión y obras (ver Tabla 1).

Veamos el caso del Maíz Amarillo Duro (MAD):

Como se observa, en el cuadro que antecede los ingresos brutos que procura las familias como resultado de su trabajo de siembra, cultivo y cosecha de Maíz Amarillo Duro ( MAD)

Tabla 1

Cantidad de Hectáreas sembradas por cultivo y cantidad de familias en posesión.

\begin{tabular}{lcc}
\hline \multirow{2}{*}{ Producto } & \multicolumn{2}{c}{ Variables } \\
\cline { 2 - 3 } & Cantidad de Hectáreas & Cantidad de Familias \\
\hline Maíz Amarillo Duro - MAD & 300,000 & $\mathbf{9 6 , 7 7 1}$ \\
Caña de Azúcar Para Azúcar & $\mathbf{8 1 , 1 4 9}$ & $\mathbf{2 6 , 1 7 7}$ \\
Frijol Castilla & $\mathbf{9 2 , 0 0 0}$ & 29,667 \\
Café & 330,000 & $\mathbf{1 0 6 , 0 0 0}$ \\
Cacao & 130,000 & $\mathbf{4 1 , 9 3 5}$ \\
TOTAL & $\mathbf{9 3 3 , 1 4 9}$ & $\mathbf{3 0 0 , 5 5 0}$ \\
\hline
\end{tabular}

Nota. Informe final de consultoría 2015 - Ministerio del Ambiente MINAM-Fuentes citadas en la Investigación.

Tabla 2

Ingresos por cantidad de hectáreas cultivadas de MAD, Según su propiedad

\begin{tabular}{|c|c|c|c|c|}
\hline $\begin{array}{c}\text { Cantidad de } \\
\text { Hectáreas (1) }\end{array}$ & $\begin{array}{l}\text { Rendimiento por } \\
\text { Hectárea (t) (2) }\end{array}$ & $\begin{array}{c}\text { Rendimiento de la } \\
\text { Parcela. (3) }\end{array}$ & $\begin{array}{c}\text { Precio de venta por } \\
\text { Tonelada S/. (4) }\end{array}$ & $\begin{array}{l}\text { Total, Ingresos } \\
\text { Anuales S/. (5) } \\
\end{array}$ \\
\hline 1 & 4.65 & 4.65 & 700.00 & 3,255 \\
\hline 2 & 4.64 & 9.3 & 700.00 & 6,510 \\
\hline 3 & 4.64 & 13.95 & 700.00 & 9,765 \\
\hline 4 & 4.65 & 18.6 & 700.00 & 13,020 \\
\hline 5 & 4.65 & 21.75 & 700.00 & 15,225 \\
\hline
\end{tabular}

Fuente: Elaboración propia.

Tabla 3

Comparación del ingreso y disponibilidad monetaria mensual promedio contra el valor de la canasta familiar básica* S/. 1,376.00 y canasta básica rural** S/. $732.00-$ MAD.

\begin{tabular}{|c|c|c|c|c|c|c|}
\hline $\begin{array}{l}\text { Ingresos } \\
\text { Brutos S/. } \\
\text { (1) }\end{array}$ & $\begin{array}{c}\text { Costos Totales } \\
50 \% \text { S/. (2) }\end{array}$ & $\begin{array}{c}\text { Beneficio } \\
\text { S/. (3) }\end{array}$ & $\begin{array}{l}\text { Meses } \\
\text { Del año } \\
\text { (4) }\end{array}$ & $\begin{array}{c}\text { Disponibilidad } \\
\text { Económica mensual } \\
\text { Anual S/. (5) }\end{array}$ & $\begin{array}{c}\text { Canasta básica } \\
\text { Alimentaria rural. INAPREF } \\
\text { 8-9/4/2019 S/. (6) }\end{array}$ & $\begin{array}{l}\text { Condición } \\
\text { Económico Social } \\
\text { (7) }\end{array}$ \\
\hline 3,255 & $1,627.50$ & $1,627.50$ & 12 & 137.70 & 732.00 & Pobre Extre \\
\hline 6,510 & $3,250.00$ & $3,250.00$ & 12 & 270.83 & 732.00 & Pobre Extre \\
\hline 9,765 & $4,882.50$ & $4,882.50$ & 12 & 406.87 & 732.00 & Pobre Extre \\
\hline 13,020 & $6,510.00$ & $6,510.00$ & 12 & 542.50 & 732.00 & Pobre Extre \\
\hline 15,225 & $7,612.50$ & $7,612.50$ & 12 & 646.70 & 732.00 & Pobre Extre \\
\hline
\end{tabular}

Fuente: Elaboración propia. 
por campaña, muestran niveles muy bajo (columna 5, Tabla 2) para el sustento de su familia durante todo un año comparado con el costo de la canasta básica familiar que, como sabemos representa la disponibilidad de dinero que requiere una familia para adquirir bienes y servicios para su subsistencia mensualmente tal como muestra la Columna (5) de la Tabla 3.

Los beneficios brutos obtenidos por las familias sembradoras del MAD al ser reducidos por efecto del valor de los costos totales se obtienen un resultado que no alcanza a cubrir la canasta básica familiar para ninguna de ellas, con lo cual todas adquieren el nivel de vida de Pobreza. Si comparamos estos ingresos en dólares que propone el PNUD igualmente resultan en niveles de pobreza estas familias (ver Tabla 4).

Veamos el caso del cultivo de la caña de azúcar.

En el caso de las más de 300,000 familias dedicadas a la siembra de la caña de azúcar se repite exactamente las mismas condiciones que se dan en el Maíz Amarillo Duro, esto lo observamos en la Tabla 5 al observar la columna 6 que es la columna en la que se compara la disponibilidad de ingresos frente al costo de la canasta básica familiar, observaremos que la disponibilidad no cubre su valor, razón por la cual el nivel de ingresos corresponde a niveles de pobreza extrema o de pobreza.

Veamos el caso del cultivo del frijol.

Para el caso del producto frijol, aun cuando este producto bien gestionado tiene la posibilidad de poder obtenerse hasta tres campañas al año, empero, el nivel de escases de recursos y desatención al sector agrario de escasos recursos por parte del estado, solo harían posible que, por propio esfuerzo del agricultor pudiera trabajar hasta dos campañas lo cual resultaría muy beneficioso para los agricultores y sus familias (ver Tabla 6).

En las columnas 6 y 7 de la Tabla 7 claramente se observar que, los ingresos de las familias que siembran estos cultivos en dos campañas anuales y, cuya posesión de la tierra son de tres a más hectáreas obtienen mejores ingresos empero, sin que estos puedan superar

Tabla 4

Ingresos por cantidad de hectáreas cultivadas de caña de azúcar según su propiedad

\begin{tabular}{ccccc}
\hline $\begin{array}{c}\text { Cantidad de } \\
\text { Hectáreas (1) }\end{array}$ & $\begin{array}{c}\text { Rendimiento por } \\
\text { hectárea (2) }\end{array}$ & $\begin{array}{c}\text { Rendimiento de la } \\
\text { Parcela. (3) }\end{array}$ & $\begin{array}{c}\text { Precio de venta por } \\
\text { Tonelada (4) }\end{array}$ & $\begin{array}{c}\text { Total, Ingresos } \\
\text { Anuales. S/ (5) }\end{array}$ \\
\hline 1 & $65,000 \mathrm{~kg}$ & $65 \mathrm{TM}$ & $\mathrm{S} / .74 .50$ & $\mathrm{~S} / .4,842.50$ \\
2 & $130,000 \mathrm{~kg}$ & $130 \mathrm{TM}$ & $\mathrm{S} / .74 .50$ & $\mathrm{~S} / .9,685.00$ \\
3 & $195,000 \mathrm{~kg}$ & $195 \mathrm{TM}$ & $\mathrm{S} / .74 .50$ & $\mathrm{~S} / .14,525.00$ \\
4 & $260,000 \mathrm{~kg}$. & $260.0 \mathrm{TM}$ & $\mathrm{S} / .74 .50$ & $\mathrm{~S} / .19,370.00$ \\
5 & $325,000 \mathrm{~kg}$. & $325.0 \mathrm{TM}$ & $\mathrm{S} / .74 .50$ & $\mathrm{~S} / .24,212.50$ \\
\hline
\end{tabular}

Fuente: Elaboración propia.

Tabla 5

Comparación del ingreso y disponibilidad monetaria mensual promedio contra el valor de la canasta familiar básica* S/. 1,376.00 y canasta básica rural** S/. 732.00 caña de azúcar.

\begin{tabular}{|c|c|c|c|c|c|c|}
\hline $\begin{array}{l}\text { Cantidad de } \\
\text { Hectáreas } \\
\text { (1) }\end{array}$ & $\begin{array}{c}\text { Total, Ingresos } \\
\text { S/. } \\
\text { (2) }\end{array}$ & $\begin{array}{l}\text { Costos } 40 \% \text { del } \\
\text { Ingreso Total S/. } \\
\text { (3) }\end{array}$ & $\begin{array}{c}\text { Disponibilidad } \\
\text { Económica Anual S/. } \\
\text { (4) }\end{array}$ & $\begin{array}{l}\text { Meses } \\
\text { Del año } \\
\text { (5) }\end{array}$ & $\begin{array}{c}\text { Disponibilidad } \\
\text { Económica mensual. S/. } \\
\text { Para la canasta } \\
\text { (6) }\end{array}$ & $\begin{array}{c}\text { Canasta S/. } \\
1,376.00^{*} \\
732.00^{* *} \\
\text { (7) }\end{array}$ \\
\hline 1 & $4,842.50$ & $1,937.00$ & $2,905.50$ & 12 & 242.15 & Pobre Ext \\
\hline 2 & $9,685.00$ & $3,874.00$ & $5,811.00$ & 12 & 484.25 & Pobre Ext \\
\hline 3 & $14,525.00$ & $5,810.00$ & $8,715.00$ & 12 & 726.25 & Pobre Ext \\
\hline 4 & $19,370.00$ & $7,748.00$ & $11,622.00$ & 12 & 968.5 & Pobre \\
\hline 5 & $24,212.50$ & $9,685.00$ & $14,527.5$ & 12 & $1,210.62$ & Pobre \\
\hline
\end{tabular}

Fuente: Elaboración propia. 
suficientemente de mejor forma su alejamiento de la líneas y zonas de pobreza.

Veamos el caso del cultivo del café.

Para el caso del producto agrario del café, si bien es cierto que, el cultivo produce mejores ingresos por efecto de sus precios en el mercado, resulta también significativa la reducción de estos por la deducción de los costos totales que resultan bastante considerables para fines del cálculo de resultados (ver Tabla 8).

La columna N. -6 de la Tabla 9 muestra que los rendimientos de las cosechas no alcanzan a cubrir con suficiencia las canastas básicas familiares, este producto se puede decir que requiere de mucho cuidado en su cultivo en virtud de ser bastante proclive a sufrir ataques de plagas, siendo la más común la roya, gorgojo, llagas del cafeto entre otras, plagas que demanda mucho cuidado del cultivo y su consecuente impacto en los costos. De otro lado el precio del café tiene su fijación en la bolsa de valores de Nueva York y de Inglaterra por ser un commoditie, y de igual forma depende también de la abundancia de oferta de café en el mundo. Estos hechos de desinformación por los productores de café de escaso recursos por parte del estado, han puesto en muchos casos en situación de una pobreza más que extrema a las

\section{Tabla 6}

Ingresos por cantidad de hectáreas cultivadas de frijol, según su propiedad

\begin{tabular}{cccccc}
\hline $\begin{array}{c}\text { Cantidad de } \\
\text { Hectáreas (1) }\end{array}$ & $\begin{array}{c}\text { Rendimiento por } \\
\text { Hectárea (t) (2) }\end{array}$ & $\begin{array}{c}\text { Precio de venta por } \\
\text { Tonelada S/. (3) }\end{array}$ & $\begin{array}{c}\text { Ingresos en S/. Para el } \\
\text { agricultor (4) }\end{array}$ & $\begin{array}{c}\text { Cantidad de } \\
\text { (5) Cosechas }\end{array}$ & $\begin{array}{c}\text { Total, Ingresos } \\
\text { S/. (6) }\end{array}$ \\
\hline 1 & $0.8 \mathrm{TM}$ & $4,000.00$ & $3,200.00$ & 2 & $6,400.00$ \\
2 & $1.6 \mathrm{TM}$ & $4,000.00$ & $6,400.00$ & 2 & $12,800.00$ \\
3 & $2.4 \mathrm{TM}$ & $4,000.00$ & $9,600.00$ & 2 & $19,200.00$ \\
4 & $3.2 \mathrm{TM}$ & $4,000.00$ & $12,800.00$ & 2 & $25,400.00$ \\
5 & $4.0 \mathrm{TM}$ & $4,000.00$ & $16,200.00$ & 2 & $32,400.00$ \\
\hline
\end{tabular}

Fuente: Elaboración propia.

Tabla 7

Comparación del ingreso y disponibilidad monetaria mensual promedio contra el valor de la canasta familiar básica* S/. 1,376.00 y canasta básica rural** S/. 732.00 - frijol

\begin{tabular}{|c|c|c|c|c|c|c|}
\hline $\begin{array}{l}\text { Cantidad de } \\
\text { Hectáreas } \\
\text { (1) }\end{array}$ & $\begin{array}{c}\text { Total, Ingresos } \\
\text { S/. } \\
\text { (2) }\end{array}$ & $\begin{array}{l}\text { Costos } 30 \% \text { del } \\
\text { Ingreso Total S/. } \\
\text { (3) }\end{array}$ & $\begin{array}{c}\text { Disponibilidad } \\
\text { Económica Anual S/. } \\
\text { (4) }\end{array}$ & $\begin{array}{c}\text { Meses } \\
\text { Del año } \\
\text { (5) }\end{array}$ & $\begin{array}{c}\text { Disponibilidad } \\
\text { Económica mensual. S/. } \\
\text { Para la canasta (6) }\end{array}$ & $\begin{array}{c}\text { Canasta } \\
\text { S/. 1,376.00 } \\
732.00 \text { (7) }\end{array}$ \\
\hline 1 & $6,400.00$ & $1,920.00$ & $4,480.00$ & 12 & 373.33 & Pobre Ext \\
\hline 2 & $12,800.00$ & $3,840.00$ & $8,960.00$ & 12 & 746.33 & Pobre Ext \\
\hline 3 & $19,200.00$ & $5,760.00$ & $13,440.00$ & 12 & $1,120.00$ & Pobre \\
\hline 4 & $25,400.00$ & $7,620.00$ & $17,780.00$ & 12 & $1,481.66$ & No Pobre \\
\hline 5 & $32,400.00$ & $9,720.00$ & $22,680.00$ & 12 & $1,890.00$ & No Pobre. \\
\hline
\end{tabular}

Fuente: Elaboración propia.

Tabla 8

Ingresos por cantidad de hectáreas cultivadas de café

\begin{tabular}{|c|c|c|c|c|c|}
\hline $\begin{array}{c}\text { Cantidad de } \\
\text { Hectáreas (1) }\end{array}$ & $\begin{array}{l}\text { Rendimiento por } \\
\text { Hectárea en Kg. (2) }\end{array}$ & $\begin{array}{l}\text { Rendimiento de la } \\
\text { Parcela. (3) }\end{array}$ & $\begin{array}{c}\text { Cantidad de Toneladas } \\
\text { (T) (4) }\end{array}$ & $\begin{array}{l}\text { Precio de venta por } \\
\text { Tonelada S/. (5) }\end{array}$ & $\begin{array}{c}\text { Total, Ingresos } \\
\text { S/. (6) }\end{array}$ \\
\hline 1 & 855 & 855 & 0.85 & 6,170 & 5,245 \\
\hline 2 & 855 & 1710 & 1.7 & 6,170 & 10,489 \\
\hline 3 & 855 & 2,565 & 2.6 & 6,170 & 16,042 \\
\hline 4 & 855 & 3,420 & 3,4 & 6,170 & 20,978 \\
\hline 5 & 855 & 4,275 & 4,3 & 6,170 & 26,531 \\
\hline
\end{tabular}

Fuente: Elaboración propia. 
familias cafetaleras. De igual forma no cuentan con los recursos económicos para adquirir plaguicidas efectivos contra las plagas, mucho menos cuentan con recursos para adquirir seguros para sus cosechas. Son tantas las calamidades por las que atraviesan estas familias, que los sembradores de café abandonan sus cultivos para ir a trabajar a las plantaciones ilegales de cultivo de coca donde obtienen salarios diarios superiores a los cien S/. 100.00 soles por día.

Veamos el caso del cacao (ver Tabla 10).

En las observaciones efectuadas al cacao se ha tomado el cultivo del cacao de consumo alimenticio y uso industrial que es el gran común del sembrío, en razón de que los cacaos de clasificación de alta calidad no son de sembríos comunes dadas las características del clima necesario para sus cultivos, los tipos de tierra, la variedad genética del cacao entre otros aspectos técnico agrarios a considerar.

Los precios de mercado del cacao son interesantes, empero, los resultados del ingreso de la campaña intervienen por los mismos factores que en los resultados de ingresos de los productos anteriores.
La Tabla 11 muestra que, en todas las situaciones de posesión de hectáreas, los ingresos no alcanzan a cubrir el costo de la canasta básica familiar para manutención mensual de la familia, ingresos que corresponden a niveles de pobreza sea esta extrema o pobreza.

\section{DISCUSIÓN}

Opiniones de instituciones nacionales e internacionales, instituciones supra nacionales, Ings, la academia nacional de investigadores independientes sobre la realidad del agro nacional, Sostienen que, los estudios realizados sobre la agricultura peruana basados en las características etnos antropológicas, sociales y culturales de las comunidades agraria del Perú, sirvieron para una época en la que el enfoque del estudio estaba basado en el análisis del modus vivendi comunitario y su relaciones inter comunitarios o grupales, estudiando en ellos también sus producciones de pan llevar como medio de subsistencia de la comuna. Nunca, estos enfoque y estudios de carácter descriptivo contemplaban las formas o mecanismos de poder integrar estas comunidades a espacios económicos urbanos, a efectos que

Tabla 9

Comparación del ingreso y disponibilidad monetaria mensual promedio contra el valor de la canasta familiar básica*S/. 1,376.00 y canasta básica rural** S/. 732.00. Café

\begin{tabular}{|c|c|c|c|c|c|c|}
\hline $\begin{array}{l}\text { Cantidad de } \\
\text { Hectáreas (1) }\end{array}$ & $\begin{array}{c}\text { Total, Ingresos } \\
\text { S/. (2) }\end{array}$ & $\begin{array}{c}\text { Costos } 40 \% \text { del } \\
\text { Ingreso Total S/. (3) }\end{array}$ & $\begin{array}{c}\text { Disponibilidad } \\
\text { Económica Anual S/. } \\
\text { (4) }\end{array}$ & $\begin{array}{c}\text { Meses } \\
\text { Del año (5) }\end{array}$ & $\begin{array}{l}\text { Disponibilidad } \\
\text { Económica } \\
\text { (6) mensual. S/ } \\
\text { Para la canasta }\end{array}$ & $\begin{array}{c}\text { Canasta } \\
\text { S/. 1,376.00 } \\
732.00 \text { (7) }\end{array}$ \\
\hline 1 & 5,245 & 2,098 & $2,542.02$ & 12 & 211.83 & Pobre Ext \\
\hline 2 & 10,489 & $4,195.60$ & $6,293.40$ & 12 & 524.45 & Pobre Ext \\
\hline 3 & 16,042 & $6,416.00$ & $9,626.00$ & 12 & 802.16 & Pobre Ext \\
\hline 4 & 20,978 & $8,391.00$ & $12,587.00$ & 12 & $1,048.91$ & Pobre \\
\hline 5 & 26,531 & $10,612.40$ & $15,918.00$ & 12 & $1,326.50$ & Pobre \\
\hline
\end{tabular}

Fuente: Elaboración propia.

Tabla 10

Ingresos por cantidad de hectáreas cultivadas de cacao, según su propiedad.

\begin{tabular}{ccccc}
\hline $\begin{array}{c}\text { Cantidad de } \\
\text { Hectáreasn(1) }\end{array}$ & $\begin{array}{c}\text { Rendimiento por } \\
\text { Hectárea Kg. (2) }\end{array}$ & $\begin{array}{c}\text { Rendimiento de la } \\
\text { Parcela. (T) (3) }\end{array}$ & $\begin{array}{c}\text { Precio de venta por } \\
\text { Tonelada S/. (4) }\end{array}$ & $\begin{array}{c}\text { Total, Ingresos } \\
\text { S/. (5) }\end{array}$ \\
\hline 1 & 800 & 0.8 & 3,780 & 3,024 \\
2 & 800 & 1.6 & 2.4 & 3,780 \\
3 & 800 & 3.2 & 3,780 & 9,072 \\
4 & 800 & 4.0 & 3.780
\end{tabular}


Tabla 11

Comparación del ingreso y disponibilidad monetaria mensual promedio contra el valor de la canasta familiar básica*S/. 1,376.00 y canasta básica rural** S/. 732.00 cacao

\begin{tabular}{|c|c|c|c|c|c|c|}
\hline $\begin{array}{l}\text { Cantidad de } \\
\text { Hectáreas } \\
\text { (1) }\end{array}$ & $\begin{array}{c}\text { Total, Ingresos } \\
\text { S/. (2) }\end{array}$ & $\begin{array}{l}\text { Costos } 40 \% \text { del } \\
\text { Ingreso Total S/. } \\
\text { (3) }\end{array}$ & $\begin{array}{c}\text { Disponibilidad } \\
\text { Económica Anual } \\
\text { S/. (4) }\end{array}$ & $\begin{array}{c}\text { Meses } \\
\text { Del año (5) }\end{array}$ & $\begin{array}{l}\text { Disponibilidad } \\
\text { Económica mensual.S/ } \\
\text { (6) Para la canasta }\end{array}$ & $\begin{array}{c}\text { Canasta } \\
\text { S/. 1,376.00 } \\
732.00 \text { (7) }\end{array}$ \\
\hline 1 & 3,024 & $1,209.60$ & $1,814.60$ & 12 & 151.21 & Pobre Ext \\
\hline 2 & 6,048 & $2,419.20$ & $3,628.80$ & 12 & 302.40 & Pobre Ext \\
\hline 3 & 9,072 & $3,628.80$ & $5,443.20$ & 12 & 453.60 & Pobre Ext \\
\hline 4 & 12,096 & $4,838.00$ & $7,258.00$ & 12 & 604.83 & Pobre Ext \\
\hline 5 & 15,120 & $6,048.00$ & $9,072.00$ & 12 & 756.00 & Pobre Ext \\
\hline
\end{tabular}

Fuente: Elaboración propia.

tuvieran participación e importancia en la dinámica de la economía nacional, de este modo, las comunidades siempre fueron mantenidas al margen de la dinámica y prospectiva de la economía central, en virtud de que, erróneamente desde el Gobierno de la Junta Militar de Gobierno del General Juan Velasco Alvarado dio la ley de Reforma agraria atomizando el agro peruano en millones de parcelas en las que, los posesionarios solo tienen un promedio de 3 hectáreas de tierra y, escaso porcentaje de ellos supera las cuatro a cinco hectáreas. Después de medio siglo millones de parceleros no tienen títulos de propiedad sobre sus tierras ni asiento alguno en Registros Públicos, esta paquidermia estatal hacen que, estos agricultores no puedan acceder a fuentes de financiamiento (De Soto, 1987), esta imposibilidad de conseguir capital de trabajo no les permite adquisición de semillas mejoradas que coadyuven al mejoramiento de los rendimientos de sus cultivos mediante la productivización de recursos como son: el agua y riego, mano de obra, uso de fertilizantes y plaguicidas orgánicos, minimización de uso de energía, maximización de uso de la mano de obra y tecnología entre otros recursos como la capacitación y uso de nueva tecnología que le permitan incrementar rendimientos de sus tierras a fin de mejorar calidades, precios y volúmenes de producción con el consecuente mejoramiento de sus ingresos y nivel de vida.

La dinámica del mercado mundial establecida por efecto de la Globalización actualmente moviliza en el mundo billones de dólares en alimentos agroindustriales, nuestro país es una enorme despensa con abundante variedades de productos agropecuarios para el mundo, gozamos del $60 \%$ de climas y microclimas que nos permiten producciones agrarias con enorme ventajas competitivas y comparativas, contamos con exquisitas frutas exóticas que el mundo aún no conoce ni ha probado, poseemos un enorme potencial agrario y agroindustrial por desarrollar con inversión propia o extranjera y, generar puestos de empleo de base y nivel que demandará el crecimiento y desarrollo del agro para los miles de profesionales, técnicos y trabajadores jóvenes $y$, el logro de la tan ansiada justicia social con equidad, reduciendo o exterminando la pobreza extrema y pobreza.

\section{CONCLUSIONES}

La investigación arriba a la conclusión sobre la necesidad de trabajar en base a patrones de ordenamiento de nuestro sistema agrario basado en territorialidad y desarrollo de potencialidades agrarias orientadas al mercado interno y externos, con desarrollo y sustento de estándares de calidad, precios y servicios, en los que, mediante políticas de estado se elabore programas integrales de concesión del abastecimiento de azúcar, café, frijol, maíz y cacao para la alimentación y nutrición en cuarteles, hospitales, comedores públicos, penales, colegios, universidades públicas, programas de alimentación, a efecto de asegurar mercado sostenido a sus proveedores y con ello mejorar los niveles de vida de miles de agricultores y familias asociadas al amparo de la ley № 29972 de asociatividad rural agraria.

El concepto de administración del agro nacional bajo enfoque de territorialidad, involucra 
estudios concienzudos de la realidad interna del sector, frente a las reales exigencias de demandas en mercados locales y externos basados en calidad, volúmenes, servicios y precios, los cuales se constituyen en objetivos y planes de acción programáticos a los cuales se les asigna recursos requeridos según presupuestos a fin de desarrollar una gestión controlada mediante indicadores de gestión - kpi, debiendo ejecutarse todo ello con enorme respeto y cuidado de sus culturas y valores de las comunidades agrícola como medio de comunicación, entendimiento y convivencia, manteniendo la credibilidad mediante cumplimiento de los acuerdos $\mathrm{y}$ convenios $\mathrm{y}$, transfiriendo conocimientos $\mathrm{y}$ tecnologías que coadyuven al mejoramiento continuo en el desempeño agrario amigable con el medio ambiente. Todo esto es posible trabajarlo mediante políticas de estado inclusivas orientadas estratégicamente al incremento de la productividad y competitividad como mecanismo y estrategia de lucha contra la pobreza.

\section{REFERENCIAS BIBLIOGRÁFICAS}

De Soto, H. (1987). El Otro Sendero; La Revolución Informal (7a. Ed.). Sudamericana.

Escobal, J. y Armas, C. (2015). Estructura agraria y dinámica de pobreza rural en el Perú. GRADE. https://www.grade.org.pe/wp-content/ uploads/ddt79.pdf

Ley № 29972, de 22 de diciembre de 2012, que promueve la inclusión de los productores agrarios a través de las cooperativas. El Peruano, pp. 481702 a 481706. https://busquedas.elperuano.pe/normaslegales/ley-que-promuevela-inclu sion-de-los-productores-agrarios-aley-n-29972-881881-4/ 